\title{
Modified proof of Caristi's fixed point theorem on partial metric spaces
}

\author{
Chakkrid Klin-eam*
}

See related article: http://www.journalofinequalitiesandapplications.com/content/2013/1/355.

\section{"Correspondence:}

chakkridk@nu.ac.th

Department of Mathematics,

Faculty of Science, Naresuan

University, Phitsanulok, 65000,

Thailand

PERDO National Centre of

Excellence in Mathematics, Faculty

of Science, Mahidol University,

Bangkok, 10400, Thailand

\begin{abstract}
In this paper, lower semi-continuous functions are used to modify the proof of Caristi's fixed point theorems on partial metric spaces. We prove a new type of fixed point theorems in complete partial metric spaces, and then generalize them to metric spaces. Some more general results are also obtained on partial metric spaces.
\end{abstract}

Keywords: lower semi-continuous functions; Caristi's fixed point theorem; partial metric spaces

\section{Introduction}

The number of extensions of the Banach contraction principle have appeared in literature. One of its most important extensions is known as Caristi's fixed point theorem because Caristi's theorem is a variety of Ekeland's $\epsilon$-variational principle [1]. In 1976, Caristi [2] proved the following fixed point theorem.

Theorem 1.1 Let $(X, d)$ be a complete metric space and $f: X \rightarrow X$, and let $\phi$ be a lower semicontinuous function from $X$ into $[0, \infty)$. Assume that $d(x, f(x)) \leq \phi(x)-\phi(f(x))$ for all $x \in X$. Then $f$ has a fixed point in $X$.

Caristi's fixed point theorem was generalized by several authors. For example, Bae [3] generalized Caristi's theorem to prove the fixed point theorem for weakly contractive setvalued mappings. Downing and Kirk [4] generalized Caristi's theorem to prove the surjectivity theorem for a nonlinear closed mapping. See also [5] and others [6, 7].

In 1977, Siegel [8] found that based on the work of Brondsted [9] (see also [1]), Caristi [2] had given a significant generalization of the contraction theorem. However, Caristi's proof, as well as other more recent ones [10], lacked the constructive aspect of the original proof. Therefore, he presented a version of Caristi's theorem which offered a construction of the fixed point as a countable iteration of application of suitable operators in a complete metric space.

In recent years many works on domain theory have been made in order to equip semantics domain with a notion of distance, see [12]. In particular, Matthews [11] introduced the notion of a partial metric space as a part of the study of denotational semantics of dataflow network, showing that the Banach contraction mapping theorem can be generalized to the partial metric context for applications in program verification.

C) 2013 Klin-eam; licensee Springer. This is an Open Access article distributed under the terms of the Creative Commons Attribution License (http://creativecommons.org/licenses/by/2.0), which permits unrestricted use, distribution, and reproduction in any medium, provided the original work is properly cited. 
In this paper we present a version of Caristi's theorem which offers a construction of the fixed point as a countable iteration of application of suitable operators in a complete partial metric space. The theorem we present is proved by a very simple argument which is in the spirit of the original contraction theorem.

\section{Preliminaries}

First, we start with some preliminaries on partial metric spaces. For more details, we refer the reader to [11].

Definition 2.1 Let $X$ be a nonempty set. The mapping $p: X \times X \rightarrow \mathbb{R}^{+}$satisfies:

(i) $p(x, x) \leq p(x, y)$ for all $x, y \in X$.

(ii) $x=y$ if and only if $p(x, x)=p(y, y)=p(x, y)$.

(iii) $p(x, y)=p(y, x)$ for all $x, y \in X$.

(iv) $p(x, y) \leq p(x, z)+p(z, y)-p(z, z)$ for all $x, y, z \in X$.

Then $p$ is called a partial metric on $X$ and $(X, p)$ is called a partial metric space.

Note that the self-distance of any point need not be zero, hence the idea of generalizing metrics so that a metric on a non-empty set $X$ is precisely a partial metric $p$ on $X$ such that $p(x, x)=0$ for any $x \in X$.

Definition 2.2 Let $(X, p)$ be a partial metric space. For any $x \in X$ and $\varepsilon>0$, we define respectively the open and closed ball for the partial metric $p$ by setting

$$
B_{\varepsilon}(x)=\{y \in X: p(x, y)<\varepsilon\}, \quad \bar{B}_{\varepsilon}(x)=\{y \in X: p(x, y) \leq \varepsilon\} .
$$

Contrary to the metric space case, some open balls may be empty. As an example, in a partial metric space $(X, p)$, the open balls $B_{p(x, x)}(x)$ are empty for any $x \in X$. For example, consider the function $p: R^{-} \times R^{-} \rightarrow R^{+}$defined by $p(x, y)=-\min \{x, y\}$ for any $x, y \in X$. Then the pair $\left(R^{-}, p\right)$ is a partial metric space. In a partial metric space $(X, p)$, the set of open balls is the basis of a $T_{0}$ topology on $X$, called the partial metric topology and denoted by $T_{[p]}$.

Lemma 2.3 Let $(X, p)$ be a partial metric space, and let $p^{s}: X \times X \rightarrow \mathbb{R}^{+} \cup\{0\}$ be defined by

$$
p^{s}(x, y)=2 p(x, y)-p(x, x)-p(y, y), \quad \forall x, y \in X .
$$

Then $\left(X, p^{s}\right)$ is a metric space.

Definition 2.4 A sequence $\left\{x_{n}\right\}$ in a partial metric space $(X, p)$ converges to $x \in X$, and we write $\lim _{n \rightarrow \infty} x_{n}=x$ if, for any $\varepsilon>0$ such that $x \in B_{\varepsilon}(x)$, there exists $N \geq 1$ so that for any $n \geq N, x_{n} \in B_{\varepsilon}(x)$.

Definition 2.5 If $\left\{x_{n}\right\}$ is a sequence in a partial metric space $(X, p)$, then $x \in X$ is a proper limit of $\left\{x_{n}\right\}$ written $x_{n} \rightarrow x$ (properly) if $x_{n} \rightarrow x$ in $\left(X, p^{s}\right)$. If a sequence has a proper limit, then one says that the sequence is properly convergent. 
Definition 2.6 A sequence $\left\{x_{n}\right\}$ in a partial metric space $(X, p)$ is called a Cauchy sequence if $\lim _{n, m \rightarrow \infty} p\left(x_{n}, x_{m}\right)$ exists and is finite. A partial metric space $(X, p)$ is said to be complete if every Cauchy sequence $\left\{x_{n}\right\}$ in $X$ converges with respect to $T_{[p]}$ to a point $x \in X$ such that $p(x, x)=\lim _{n, m \rightarrow \infty} p\left(x_{n}, x_{m}\right)$.

The following lemma on a partial metric space can be derived easily (see, e.g., [11, 12]).

Lemma 2.7 Let $(X, p)$ be a partial metric space. Then

(i) a sequence $\left\{x_{n}\right\}$ in a partial metric space $(X, p)$ converges to a point $x \in X$ if and only if $p(x, x)=\lim _{n \rightarrow \infty} p\left(x, x_{n}\right)$,

(ii) a sequence $\left\{x_{n}\right\}$ in a partial metric space $(X, p)$ converges properly to a point $x \in X$ if and only if $p(x, x)=\lim _{n \rightarrow \infty} p\left(x_{n}, x_{n}\right)=\lim _{n \rightarrow \infty} p\left(x, x_{n}\right)$,

(iii) a sequence $\left\{x_{n}\right\}$ in a partial metric space $(X, p)$ is a Cauchy sequence if and only if it is a Cauchy sequence in the metric $\left(X, p^{s}\right)$,

(iv) a partial metric space $(X, p)$ is complete if and only if the metric space $\left(X, p^{s}\right)$ is complete. Moreover,

$$
p(x, x)=\lim _{n \rightarrow \infty} p\left(x_{n}, x_{n}\right)=\lim _{n \rightarrow \infty} p\left(x, x_{n}\right) \quad \Leftrightarrow \quad \lim _{n \rightarrow \infty} p^{s}\left(x, x_{n}\right)=0
$$

Definition 2.8 A function $f: X \rightarrow \mathbb{R}$ is called lower semi-continuous if for any sequence $\left\{x_{n}\right\}$ in $X$ and $x \in X$ such that $\left\{x_{n}\right\}$ converges to $x$, we have $f(x) \leq \liminf _{n \rightarrow \infty} f\left(x_{n}\right)$.

\section{Main results}

Let $(X, p)$ be a complete partial metric space. Let $\phi: X \rightarrow \mathbb{R}^{+}$and $g: X \rightarrow X$ be not necessarily continuous functions such that

$$
2 p(x, g(x))-p(x, x)-p(g(x), g(x)) \leq \phi(x)-\phi(g(x)), \quad x \in X .
$$

Given a sequence of functions $f_{i}, 1 \leq i<\infty$,

$$
\prod_{i=1}^{\infty} f_{i}(x)=\lim _{i \rightarrow \infty} f_{i} f_{i-1} \cdots f_{1}(x)
$$

If it exists, call it the countable composition of the $f_{i}$.

Now, we let $\Phi=\{f \mid f: X \rightarrow X$ and $2 p(x, f(x))-p(x, x)-p(f(x), f(x)) \leq \phi(x)-\phi(f(x))\}$, $\Phi_{g}=\{f \mid f \in \Phi$ and $\phi(f) \leq \phi(g)\}$, and then we prove a simple lemma as follows.

Lemma 3.1 Both $\Phi$ and $\Phi_{g}$ are closed under compositions. Moreover, if $\phi$ is lower semicontinuous, then $\Phi$ and $\Phi_{g}$ are closed under countable compositions.

Proof We first show that $\Phi$ is closed under compositions.

Let $f_{1}$ and $f_{2}$ be in $\Phi$, then we have

$$
\begin{aligned}
2 p & \left(x, f_{2} f_{1}(x)\right)-p(x, x)-p\left(f_{2} f_{1}(x), f_{2} f_{1}(x)\right) \\
\leq & 2\left[p\left(x, f_{1}(x)\right)+p\left(f_{1}(x), f_{2} f_{1}(x)\right)-p\left(f_{1}(x), f_{1}(x)\right)\right] \\
& -p(x, x)-p\left(f_{2} f_{1}(x), f_{2} f_{1}(x)\right)
\end{aligned}
$$




$$
\begin{aligned}
= & 2 p\left(x, f_{1}(x)\right)+2 p\left(f_{1}(x), f_{2} f_{1}(x)\right)-2 p\left(f_{1}(x), f_{1}(x)\right) \\
& -p(x, x)-p\left(f_{2} f_{1}(x), f_{2} f_{1}(x)\right) \\
= & 2 p\left(x, f_{1}(x)\right)+2 p\left(f_{1}(x), f_{2} f_{1}(x)\right)-p\left(f_{1}(x), f_{1}(x)\right) \\
& -p\left(f_{1}(x), f_{1}(x)\right)-p(x, x)-p\left(f_{2} f_{1}(x), f_{2} f_{1}(x)\right) \\
= & {\left[2 p\left(x, f_{1}(x)\right)-p(x, x)-p\left(f_{1}(x), f_{1}(x)\right)\right] } \\
& +\left[2 p\left(f_{1}(x), f_{2} f_{1}(x)\right)-p\left(f_{1}(x), f_{1}(x)\right)-p\left(f_{2} f_{1}(x), f_{2} f_{1}(x)\right)\right] \\
\leq & \phi(x)-\phi\left(f_{1}(x)\right)+\phi\left(f_{1}(x)\right)-\phi\left(f_{2} f_{1}(x)\right) \\
= & \phi(x)-\phi\left(f_{2} f_{1}(x)\right)
\end{aligned}
$$

implies that $f_{2} f_{1} \in \Phi$.

Furthermore, we have $\Phi_{g}$ is closed under compositions.

Indeed, we let $f_{1} \in \Phi_{g}$, which gives that $\phi\left(f_{1}(x)\right) \leq \phi(g(x))$, and we now consider

$$
\begin{aligned}
\phi\left(f_{1}(x)\right)-\phi\left(f_{2} f_{1}(x)\right) \geq & 2 p\left(f_{2} f_{1}(x), f_{1}(x)\right)-p\left(f_{2} f_{1}(x), f_{2} f_{1}(x)\right)-p\left(f_{1}(x), f_{1}(x)\right) \\
= & p\left(f_{2} f_{1}(x), f_{1}(x)\right)+p\left(f_{2} f_{1}(x), f_{1}(x)\right)-p\left(f_{2} f_{1}(x), f_{2} f_{1}(x)\right) \\
& -p\left(f_{1}(x), f_{1}(x)\right) \\
\geq & p\left(f_{2} f_{1}(x), f_{1}(x)\right)+p\left(f_{2} f_{1}(x), f_{1}(x)\right)-p\left(f_{2} f_{1}(x), f_{1}(x)\right) \\
& -p\left(f_{1}(x), f_{2} f_{1}(x)\right) \\
= & 0 .
\end{aligned}
$$

So, we obtain from the above inequalities that

$$
0 \leq \phi\left(f_{1}(x)\right)-\phi\left(f_{2} f_{1}(x)\right) \leq \phi(g(x))-\phi\left(f_{2} f_{1}(x)\right)
$$

and then $\phi\left(f_{2} f_{1}\right) \leq \phi(g)$. This implies that $f_{2} f_{1} \in \Phi_{g}$.

Therefore $\Phi$ and $\Phi_{g}$ are closed under compositions.

To show the classes are closed under countable composition, we use the following lemma.

Lemma 3.2 Let $\left\{x_{n}\right\}$ be a sequence in a partial metric space $(X, p)$ such that

$$
2 p\left(x_{n+1}, x_{n}\right)-p\left(x_{n+1}, x_{n+1}\right)-p\left(x_{n}, x_{n}\right) \leq \phi\left(x_{n}\right)-\phi\left(x_{n+1}\right), \quad \forall n \in \mathbb{N},
$$

then $\lim _{n \rightarrow \infty} x_{n}=\bar{x}$ and $2 p\left(\bar{x}, x_{n}\right)-p(\bar{x}, \bar{x})-p\left(x_{n}, x_{n}\right) \leq \phi\left(x_{n}\right)-\phi(\bar{x})$, for each $n$, where $\phi$ is a lower semi-continuous function.

Proof We will prove that $\lim _{n \rightarrow \infty} x_{n}=\bar{x}$ and

$$
2 p\left(\bar{x}, x_{n}\right)-p(\bar{x}, \bar{x})-p\left(x_{n}, x_{n}\right) \leq \phi\left(x_{n}\right)-\phi(\bar{x}) .
$$


We note that

$$
2 p\left(x_{n+1}, x_{n}\right)-p\left(x_{n+1}, x_{n+1}\right)-p\left(x_{n}, x_{n}\right) \leq \phi\left(x_{n}\right)-\phi\left(x_{n+1}\right), \quad \forall n \in \mathbb{N},
$$

and we see that

$$
\begin{aligned}
2 p\left(x_{n+1}, x_{n}\right)-p\left(x_{n+1}, x_{n+1}\right)-p\left(x_{n}, x_{n}\right) & \geq 2 p\left(x_{n+1}, x_{n}\right)-p\left(x_{n+1}, x_{n}\right)-p\left(x_{n}, x_{n+1}\right) \\
& =2 p\left(x_{n+1}, x_{n}\right)-p\left(x_{n+1}, x_{n}\right)-p\left(x_{n+1}, x_{n}\right) \\
& =0 .
\end{aligned}
$$

It follows that

$$
0 \leq \phi\left(x_{n}\right)-\phi\left(x_{n+1}\right), \quad \forall n \in \mathbb{N} .
$$

Thus

$$
\phi\left(x_{1}\right) \geq \phi\left(x_{2}\right) \geq \cdots \geq \phi\left(x_{n}\right) \geq \phi\left(x_{n+1}\right) \geq \cdots>0,
$$

and then the sequence of value $\phi\left(x_{n}\right)$ is decreasing and bounded below, which implies that $\left\{\phi\left(x_{n}\right)\right\}$ is a convergent sequence in $\mathbb{R}$, that is, a Cauchy sequence. Thus, for $\varepsilon>0$, there exists $n_{0} \in \mathbb{N}$ such that for all $m>n>n_{0}$, we have

$$
\left|\phi\left(x_{n}\right)-\phi\left(x_{m}\right)\right|<\varepsilon
$$

By the triangle inequality, we have

$$
2 p\left(x_{n}, x_{m}\right)-p\left(x_{n}, x_{n}\right)-p\left(x_{m}, x_{m}\right) \leq \phi\left(x_{n}\right)-\phi\left(x_{m}\right) .
$$

Therefore

$$
2 p\left(x_{n}, x_{m}\right)-p\left(x_{n}, x_{n}\right)-p\left(x_{m}, x_{m}\right) \leq\left|\phi\left(x_{n}\right)-\phi\left(x_{m}\right)\right|<\varepsilon .
$$

It follows that $p^{s}\left(x_{n}, x_{m}\right)<\varepsilon$. Thus $\left\{x_{n}\right\}$ is a Cauchy sequence in $X$, and the completeness of the space $\left(X, p^{s}\right)$ implies that $\left\{x_{n}\right\}$ converges and so there exists $\bar{x} \in X$ such that $\lim _{n \rightarrow \infty} x_{n}=\bar{x}$. Moreover, we have

$$
\begin{aligned}
2 p\left(x_{n}, \bar{x}\right)-p\left(x_{n}, x_{n}\right)-p(\bar{x}, \bar{x}) & =p^{s}\left(x_{n}, \bar{x}\right)=\lim _{m \rightarrow \infty} p^{s}\left(x_{n}, x_{m}\right) \\
& \leq \lim _{m \rightarrow \infty}\left[\phi\left(x_{n}\right)-\phi\left(x_{m}\right)\right] \\
& =\lim _{m \rightarrow \infty} \phi\left(x_{n}\right)-\lim _{m \rightarrow \infty} \phi\left(x_{m}\right) \\
& =\phi\left(x_{n}\right)-\lim _{m \rightarrow \infty} \phi\left(x_{m}\right) \\
& \leq \phi\left(x_{n}\right)-\liminf _{m \rightarrow \infty} \phi\left(x_{m}\right) \\
& \leq \phi\left(x_{n}\right)-\phi(\bar{x}) .
\end{aligned}
$$

This last inequality obtained by $\phi$ is lower semi-continuous.

Therefore $2 p\left(\bar{x}, x_{n}\right)-p(\bar{x}, \bar{x})-p\left(x_{n}, x_{n}\right) \leq \phi\left(x_{n}\right)-\phi(\bar{x})$. 
The remainder of the proof of Lemma 3.1 amounts to the observation that for each $x \in X$, the sequence $x_{i}=f_{i} f_{i-1} \cdots f_{1}(x)$ satisfies the conditions of Lemma 3.2. Before starting the main theorem of this paper, we also need the following.

Definition 3.3 Let $(X, p)$ be a partial metric space.

(1) For $A \subseteq X$, define the diameter of $A$, written $D(A)$, by

$$
D(A)=\sup _{x_{i}, x_{j} \in A}\left(2 p\left(x_{i}, x_{j}\right)-p\left(x_{i}, x_{i}\right)-p\left(x_{j}, x_{j}\right)\right) .
$$

(2) Let $r(A)=\inf _{x \in A}(\phi(x))$; note $B \subseteq A$ implies $r(B) \geq r(A)$.

(3) Let $\Phi^{\prime} \subseteq \Phi$. For each $x \in X$, define $S_{x}=\left\{f(x) \mid f \in \Phi^{\prime}\right\}$.

Lemma 3.4 $D\left(S_{x}\right) \leq 2\left(\phi(x)-r\left(S_{x}\right)\right)$.

Proof Let $f_{1}, f_{2}$ be in $S_{x}$, then we have

$$
\begin{aligned}
2 p\left(f_{1}(x), f_{2}(x)\right)-p\left(f_{1}(x), f_{1}(x)\right)-p\left(f_{2}(x), f_{2}(x)\right) \\
\leq 2 p\left(f_{1}(x), x\right)+2 p\left(x, f_{2}(x)\right)-2 p(x, x) \\
\quad-p\left(f_{1}(x), f_{1}(x)\right)-p\left(f_{2}(x), f_{2}(x)\right) \\
=2 p\left(f_{1}(x), x\right)+2 p\left(x, f_{2}(x)\right)-p(x, x)-p(x, x) \\
\quad-p\left(f_{1}(x), f_{1}(x)\right)-p\left(f_{2}(x), f_{2}(x)\right) \\
=\left[2 p\left(f_{1}(x), x\right)-p\left(f_{1}(x), f_{1}(x)\right)-p(x, x)\right] \\
\quad+\left[2 p\left(x, f_{2}(x)\right)-p\left(f_{2}(x), f_{2}(x)\right)-p(x, x)\right] \\
=\left[2 p\left(x, f_{1}(x)\right)-p(x, x)-p\left(f_{1}(x), f_{1}(x)\right)\right] \\
\quad+\left[2 p\left(x, f_{2}(x)\right)-p(x, x)-p\left(f_{2}(x), f_{2}(x)\right)\right] \\
\leq\left[\phi(x)-\phi\left(f_{1}(x)\right)\right]+\left[\phi(x)-\phi\left(f_{2}(x)\right)\right] \\
=2 \phi(x)-\phi\left(f_{1}(x)\right)-\phi\left(f_{2}(x)\right) \\
=2\left(\phi(x)-r\left(S_{x}\right)\right) .
\end{aligned}
$$

Thus $D\left(S_{x}\right) \leq 2\left(\phi(x)-r\left(S_{x}\right)\right)$.

Theorem 3.5 Let $\Phi^{\prime} \subseteq \Phi$ be closed under compositions. Let $x_{0} \in X$.

1. Let $\Phi^{\prime}$ be closed under countable compositions. Then there exists an $\bar{f} \in \Phi^{\prime}$ such that $\bar{x}=\bar{f}\left(x_{0}\right)$ and $g(\bar{x})=\bar{x}$ for all $g \in \Phi^{\prime}$.

2. Let the elements of $\Phi^{\prime}$ be continuous functions. Then there exists a sequence of functions $f_{i} \in \Phi^{\prime}$ and $\bar{x}=\lim _{i \rightarrow \infty} f_{i} f_{i-1} \cdots f_{1}\left(x_{0}\right)$ such that $g(\bar{x})=\bar{x}$ for all $g \in \Phi^{\prime}$.

Proof Let $\varepsilon_{i}$ be a positive sequence converging to 0 . Choose $f_{1} \in \Phi^{\prime}$ such that

$$
\phi\left(f_{1}\left(x_{0}\right)\right)-r\left(S_{x_{0}}\right)<\frac{\varepsilon_{1}}{2} .
$$

Set $x_{1}=f_{1}\left(x_{0}\right)$. 
Since $\Phi^{\prime}$ is closed under compositions, we have $S_{x_{1}} \subseteq S_{x_{0}}$ and

$$
\begin{aligned}
D\left(S_{x_{1}}\right) & \leq 2\left(\phi\left(x_{1}\right)-r\left(S_{x_{1}}\right)\right) \\
& \leq 2\left(\phi\left(f_{1}\left(x_{0}\right)\right)-r\left(S_{x_{0}}\right)\right) \\
& <2\left(\frac{\varepsilon_{1}}{2}\right) \\
& =\varepsilon_{1} .
\end{aligned}
$$

Again, choose $f_{2} \in \Phi^{\prime}$ such that

$$
\phi\left(f_{2}\left(x_{1}\right)\right)-r\left(S_{x_{1}}\right)<\frac{\varepsilon_{2}}{2} .
$$

Set $x_{2}=f_{2}\left(x_{1}\right)$.

Since $\Phi^{\prime}$ is closed under compositions, we have $S_{x_{2}} \subseteq S_{x_{1}}$ and

$$
\begin{aligned}
D\left(S_{x_{2}}\right) & \leq 2\left(\phi\left(x_{2}\right)-r\left(S_{x_{2}}\right)\right) \\
& \leq 2\left(\phi\left(f_{2}\left(x_{1}\right)\right)-r\left(S_{x_{1}}\right)\right) \\
& <2\left(\frac{\varepsilon_{2}}{2}\right) \\
& =\varepsilon_{2} .
\end{aligned}
$$

Continuing this procedure, we obtain a sequence of $f_{i}$ such that

$$
x_{i+1}=f_{i+1}\left(x_{i}\right), S_{x_{i+1}} \subseteq S_{x_{i}} \text { and } D\left(S_{x_{i+1}}\right)<\varepsilon_{i+1} .
$$

Next, to show that $g(\bar{x})=\bar{x}$ under hypothesis 1 . Let $\bar{f}=\prod_{i=1}^{\infty} f_{i}$ and $\bar{x}=\bar{f}\left(x_{0}\right)$. Since $\Phi^{\prime}$ is closed under compositions, then $\bar{f} \in \Phi^{\prime}$. Since $\bar{x}=\prod_{j=i+1}^{\infty} f_{j}\left(x_{i}\right)$, it implies that $\bar{x} \in S_{x_{i}}$ for each $i$. On the other hand, since $\lim _{i \rightarrow \infty} D\left(S_{x_{i}}\right)=0$, we have $\bar{x}=\bigcap_{i=0}^{\infty} S_{x_{i}}$. Since $g(\bar{x})=$ $g\left(\prod_{j=i+1}^{\infty} f_{j}\left(x_{i}\right)\right)$, we obtain that $g(\bar{x}) \in S_{x_{i}}$. Thus $g(\bar{x})=\bar{x}$. Finally, to show that $g(\bar{x})=\bar{x}$ under hypothesis 2. Let $\bar{x}=\lim _{i \rightarrow \infty} f_{i} f_{i-1} \cdots f_{1}\left(x_{0}\right)=\lim _{i \rightarrow \infty} x_{i}$. First, since $\left\{x_{j}\right\}_{j>i} \subseteq S_{i}$, for each $i$ we have that $\bar{x} \in \bar{S}_{i}$, the closure of $S_{i}$. Since $D\left(\bar{S}_{i}\right)=D\left(S_{i}\right)$, we have that $\bar{x}=\bigcap_{i=0}^{\infty} S_{x_{i}}$.

To verify that $g(\bar{x})=\bar{x}$, observe that $g\left(x_{i}\right) \in S_{x_{i}}$ for each $i$. Hence, for any $\frac{\varepsilon}{2}>0$, there exists $i_{0}$ such that $B_{\frac{\varepsilon}{2}}(g(\bar{x})) \cap S_{x_{i}} \neq \emptyset, i>i_{0}$ (here we need $g$ to be continuous). Therefore, for $i>i_{0}$,

$$
\begin{aligned}
2 p(\bar{x}, g(\bar{x}))-p(\bar{x}, \bar{x})-p(g(\bar{x}), g(\bar{x})) \\
\leq 2\left[p\left(\bar{x}, g\left(x_{i}\right)\right)+p\left(g\left(x_{i}\right), g(\bar{x})\right)-p\left(g\left(x_{i}\right), g\left(x_{i}\right)\right)\right] \\
\quad-p(g(\bar{x}), g(\bar{x}))-p(\bar{x}, \bar{x}) \\
=2 p\left(\bar{x}, g\left(x_{i}\right)\right)+2 p\left(g\left(x_{i}\right), g(\bar{x})\right)-2 p\left(g\left(x_{i}\right), g\left(x_{i}\right)\right) \\
\quad-p(g(\bar{x}), g(\bar{x}))-p(\bar{x}, \bar{x}) \\
=2 p\left(\bar{x}, g\left(x_{i}\right)\right)+2 p\left(g\left(x_{i}\right), g(\bar{x})\right)-p(\bar{x}, \bar{x}) \\
\quad-p\left(g\left(x_{i}\right), g\left(x_{i}\right)\right)-p\left(g\left(x_{i}\right), g\left(x_{i}\right)\right)-p(g(\bar{x}), g(\bar{x}))
\end{aligned}
$$




$$
\begin{aligned}
& <2 p\left(g(\bar{x}), g\left(x_{i}\right)\right)+\left[2 p\left(\bar{x}, g\left(x_{i}\right)\right)-p(\bar{x}, \bar{x})-p\left(g\left(x_{i}\right), g\left(x_{i}\right)\right)\right] \\
& <2\left(\frac{\varepsilon}{2}\right)+\varepsilon_{i} \\
& =\varepsilon+\varepsilon_{i} .
\end{aligned}
$$

And so $\varepsilon_{i} \rightarrow 0$ implies that

$$
2 p(g(\bar{x}), \bar{x})-p(g(\bar{x}), g(\bar{x}))-p(\bar{x}, \bar{x}) \leq \varepsilon .
$$

Therefore $g(\bar{x})=\bar{x}$. The proof is completed.

Remark In Theorem 3.5(2) one may choose $\Phi^{\prime}=\left\{g^{n}\right\}$, the set consisting of $g$ and its finite iterates. For this choice of $\Phi^{\prime}$, one has $\bar{x}=\lim _{n \rightarrow \infty} g^{n}\left(x_{0}\right)$ as in the contraction theorem.

\section{Competing interests}

The author declares that they have no competing interests.

\section{Acknowledgements}

The author is grateful to the referees for precise remarks allowing us to improve the presentation of the paper and would like to thank the faculty of Science, Naresuan University, Phitsanulok for the financial support.

Received: 25 December 2012 Accepted: 12 April 2013 Published: 26 April 2013

\section{References}

1. Ekeland, I: Sur les problemes variationnels. C. R. Acad. Sci. Paris 275, 1057-1059 (1972)

2. Caristi, J: Fixed point theorems for mappings satisfying inwardness conditions. Trans. Am. Math. Soc. 215, 241-251 (1976)

3. Bae, JS: Fixed point theorems for weakly contractive multivalued maps. J. Math. Anal. Appl. 284, $690-697$ (2003)

4. Downing, D, Kirk, WA: A generalization of Caristi's theorem with applications to nonlinear mapping theory. Pac. J. Math. 69, 339-346 (1977)

5. Bae, JS, Cho, EW, Yeom, SH: A generalization of the Caristi-Kirk fixed point theorem and its applications to mapping theorems. J. Korean Math. Soc. 31, 29-48 (1994)

6. Reich, S: Approximate selections best approximations fixed points and invariant set. J. Math. Anal. Appl. 62, 104-113 (1978)

7. De Blasi, FS, Myjak, J, Reich, S, Zaslavski, AJ: Generic existence and approximation of fixed points for nonexpansive set-valued maps. Set-Valued Var. Anal. 17, 97-112 (2009)

8. Siegel, J: A new proof of Caristi's fixed point theorem. Proc. Am. Math. Soc. 66, 54-56 (1977)

9. Brondsted, A: On a lemma of Bishop and Phelps. Pac. J. Math. 55, 335-341 (1974)

10. Wong, CS: On a fixed point theorem of contractive type. Proc. Am. Math. Soc. 57, 283-284 (1976)

11. Matthews, SG: Partial metric topology. In: Proc. 8th Summer Conference on General Topology and Applications. Ann. New York Acad. Sci., vol. 728, pp. 183-197 (1994)

12. Valero, O: On Banach fixed point theorems for partial metric spaces. Appl. Gen. Topol. 6, 229-240 (2005) 